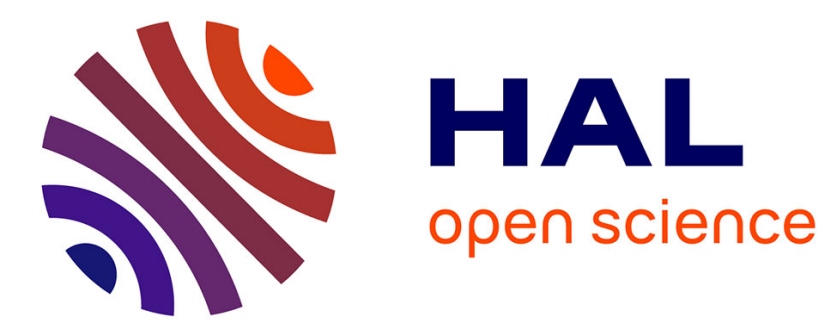

\title{
What Level of Competition Intensity Maximises Investment in the Wireless Industry?
}

Georges Vivien Houngbonon, François Jeanjean

\section{To cite this version:}

Georges Vivien Houngbonon, François Jeanjean. What Level of Competition Intensity Maximises Investment in the Wireless Industry?. Telecommunications Policy, 2016, 40 (8), p.774-790. 10.1016/j.telpol.2016.04.001 . hal-01653797

\section{HAL Id: hal-01653797 https://hal.science/hal-01653797}

Submitted on 1 Dec 2017

HAL is a multi-disciplinary open access archive for the deposit and dissemination of scientific research documents, whether they are published or not. The documents may come from teaching and research institutions in France or abroad, or from public or private research centers.
L'archive ouverte pluridisciplinaire HAL, est destinée au dépôt et à la diffusion de documents scientifiques de niveau recherche, publiés ou non, émanant des établissements d'enseignement et de recherche français ou étrangers, des laboratoires publics ou privés. 


\title{
What Level of Competition Intensity Maximises Investment in the Wireless Industry?*
}

\author{
Georges Vivien Houngbonon ${ }^{\dagger}$ \\ François Jeanjean
}

12th April 2016

\begin{abstract}
This paper investigates the relationship between competition and investment in the wireless industry from a dynamic perspective. Using firm level data and instrumental variable estimation strategy, it finds that the relationship is inverted-U shaped. The investment maximising intensity of competition is reached when operators' gross profits represent 37 or 40 percent of their revenues, depending on whether capital expenditures are normalised by the number of subscribers. This finding means that investment increases with competition as long as operators' profits are above the thresholds of 37 or 40 percent of their revenues. Under these thresholds, there is a tradeoff between competition and investment. The paper also finds a significant long run effect of competition on investment which amplifies the short run effect by a factor of 3 to 4 .
\end{abstract}

Keywords: Competition, Investment, Mobile Telecommunications.

JEL Classification: D21, D22, L13, L40.

*We would like to thank Jérôme Pouyet, Marc Lebourges, Bruno Jullien, Wilfried SandZantman, Marc Petulowa, Maude Hasbi, Julienne Liang, Olivia Bertelli and the seminar participants at the Paris School of Economics, as well as the participants at the International Telecommunications Society Regional Conference 2014 in Brussels, the Telecommunications Policy Research Conference 2014 in Arlington and the Journee de Microeconomie Appliquee 2015 in Montpellier. Financial support from Orange and the CEPREMAP is gratefully acknowledged. This paper also benefits from valuable suggestions from two anonymous referees. All errors are ours.

${ }^{\dagger}$ Paris School of Economics \& Toulouse School of Economics - IDEI, gvivienh@gmail.com

‡Orange, francois.jeanjean@orange.com 


\section{Introduction}

The relationship between competition and investment is the topic of a vast body of economic literature. Although the debate on the issue has been lively for many decades, no clear-cut conclusion has been reached so far. There are two main opposing views about the nature of this relationship. The Schumpeterian view highlights that large firms in more concentrated markets are more likely to invest, while the Arrow's view emphasises the virtues of competition, which stimulates investment to escape competition. ${ }^{1}$ Theoretically, the relationship between competition and investment is ambiguous. For instance, Sacco and Schmutzler (2011) find a U-shaped relationship, whereas Belleflamme and Vergari (2011) predicts an inverted-U shaped relationship. Schmutzler (2013) argues that: "The relationship between competition and investment is not affected in an unambiguous way by the level of pre-existing competition". As the theory is not conclusive, empirical evidence is needed for each specific industry.

This paper takes advantage of firm level data on wireless operators worldwide to estimate the relationship between competition and investment in the wireless industry. The intensity of competition is measured at the firm level on the basis of the Lerner index of monopoly power, and investment is measured as total or per subscriber capital expenditures. Some empirical papers investigate the relationship between competition and investment in the wireless industry, but they all assume a linear relationship and do not correct for the endogeneity of competition. ${ }^{2}$ This paper employs non-parametric identification strategies, in particular, a locally weighted scatterplot smoothing and a local polynomial smoothing to identify the shape of the relationship without making any a priori assumption. It corrects for endogeneity by using an instrumental variable estimation strategy and a Generalised Method of Moments estimator. The causal impact of competition on investment stems from cross-operators differences in competition intensity due to their date of entry into the market and lags of competition intensity. The paper also accounts for the speed of adjustment of investment in the wireless industry by formulating a dynamic model linking investment to a quadratic function of competition, controlling for the lagged values of investment as well as market and operators' characteristics.

The non-parametric methods suggest an inverted-U shaped relationship between

\footnotetext{
${ }^{1}$ See Schumpeter (1942) and Arrow (1962).

${ }^{2}$ See Garrone and Zaccagnino (2015) who find no correlation between competition and investment in fixed and mobile networks, and Kang et al. (2012) who find a positive correlation between market concentration and investment in the Chinese wireless market.
} 
competition and investment in the wireless industry. This finding is confirmed by the econometric estimation and is robust to alternative measures of investment, modelling specifications and estimators. The relationship is also robust to heterogeneity in terms of demand and cost parameters such as market size and network deployment cost. More specifically, a wireless operator's investment increases with competition as long as its profit is above the thresholds of 37 or 40 percent of its total revenue. These thresholds depend on whether or not capital expenditures are normalised by the number of subscribers. Under these thresholds, there is a tradeoff between competition and investment as more competition lowers operators' investment in wireless networks. In addition, the estimates suggest a significant long run effect of competition on investment which amplifies the short run effect by a factor of 3 to 4 .

The rest of the paper is organised as follows. Section 2 summarises the findings from the literature on the relationship between competition and investment. Section 3 provides some background information to motivate the analysis of the link between competition and investment in the wireless industry. Section 4 presents the dataset and the variables used in the empirical analysis. Section 5 describes the econometric model and the estimation strategy. Section 6 presents and discusses the results along with their policy implications. Section 7 summarises the main findings and concludes.

\section{Related literature}

As reviewed by Mathis and Sand-Zantman (2014), most papers dealing with the relationship between competition and investment focus on investment in process or product innovation. ${ }^{3}$ According to Boone (2000), investment in process innovation lowers the marginal cost of production for a given product, whereas investment in product innovation affects consumers' preferences. This latter introduces new products without necessarily affecting the quality or the marginal cost of production of existing products. Investment in wireless networks can be viewed as expenditures in both process and product innovation. Not only, it reduces the marginal cost of each unit of information due to technological progress, but also it introduces new product into the market. ${ }^{4}$ Therefore, the findings from the literature on the

\footnotetext{
${ }^{3}$ Note that some papers like Tang (2006) argue that firms' perceptions of the intensity of competition are also important determinants of innovation.

${ }^{4}$ In practice, wireless services based on new technologies are often labelled as a product innovation. This is true from consumers' perspective as they purchase greater allowance at the same
} 
relationship between competition and innovation apply to the wireless industries.

The relationship between competition and innovation is the subject of a long standing debate initiated by Schumpeter (1942) and Arrow (1962). Two conflicting views lie at the heart of this debate. On the one hand, Schumpeter points out the role of firm's size, financial constraints and more specifically the incentive of a monopoly to invest more than a firm in a competitive market (Schumpeter, 1942). ${ }^{5}$ This view is driven by the efficiency effect as epitomised by the findings of Gilbert and Newbery (1982). The efficiency effect refers to the theoretical finding that an efficient monopolist always gets bigger profit than two uncoordinated duopolists altogether. ${ }^{6}$ The argument made by Gilbert and Newbery can be summarised as follows: due to the efficiency effect, a monopolist would lose more than a potential entrant by not innovating. ${ }^{7}$

On the other hand, Arrow's view emphasises that a firm in a competitive market has more incentive to innovate than a monopoly due to the escape-competition effect (Arrow, 1962). The escape-competition effect corresponds to the profit advantage of being the technological leader in a competitive market, compared to a monopoly. Indeed, when investment in a cost-reducing technology yields an exclusive and unlimited right, the difference between ex-ante and ex-post profits is larger in a competitive market than in a monopoly. This is because a firm in a competitive market earns lower profit ex-ante compared to a monopoly. However, the Arrow's view can also be interpreted as a replacement effect because the monopoly has lower incentive to invest in a new technology due to the opportunity cost of replacing its old technology (Tirole, 1988).

In a general equilibrium framework, the empirical findings are mixed. For instance, Blundell et al. (1999) find that larger firms invest more than smaller ones, while those in more concentrated markets invest less. Likewise, Kraft (1989) finds a negative relationship between the number of competitors and the percentage of sales attributable to new products, whereas Nickell (1996) identifies a positive relationship between the number of competitors and total factor productivity growth for

price. However, from the firm's perspective, they actually correspond to process innovations.

${ }^{5} \mathrm{He}$ also emphasises the role of competition in the form of a threat of entry.

${ }^{6}$ See Tirole (1988), chap. 8, section 8.6.2.1 for an exposition of this effect.

${ }^{7}$ Consider a race for innovation between an incumbent monopoly an a potential entrant. Winning the race amounts to a reduction in the marginal cost of production from $\bar{c}$ to $\underline{c}$. If the entrant wins the race, it gains the asymmetric duopoly profit denoted by $\Pi^{d}(\underline{c})$, whereas the incumbent's profit becomes $\Pi^{d}(\bar{c})$. In case the monopoly wins the race, it gains the efficient monopoly profit $\Pi^{m}(\underline{c})$. The monopolist incentive to win the race is the difference $\Pi^{m}(\underline{c})-\Pi^{d}(\bar{c})$, whereas the entrant's incentive to invest is $\Pi^{d}(\underline{c})$. Because of the efficiency effect, $\Pi^{m}(\underline{c})-\Pi^{d}(\bar{c})>\Pi^{d}(\underline{c})$. Therefore, the monopoly has more incentive to invest in order to win the race than the entrant. 
British companies. Aghion et al. (2005) show, both theoretically and empirically, an inverted-U shaped relationship between competition and innovation. In their general equilibrium model, the central force driving the inverted- $U$ shaped relationship is the technological gap between firms within each industry. As the technological gap increases, more competition lowers incentives to innovate.

In a partial equilibrium framework, Schmutzler (2013) relies on a single parameter of competition, in the tradition of Boone (2008), and shows that the relationship between competition and investment can take various shapes. He emphasises four channels through which competition affects investment in cost-reducing technologies. The margin effect is negative as more competition reduces the marginal profit from investment. The output sensitivity effect is positive as more competition reallocates output towards the more efficient firms. The output effect depends on cost asymmetry between firms. It is negative for less efficient firms and positive for the more efficient ones. Finally, the cost pass-through effect characterises the extent to which cost reduction is passed to the consumers in terms of lower prices. It is positive for Cournot competition and negative for Bertrand competition. The overall effect of competition on investment is the sum of these four effects, the sign of which is indeterminate.

Specific theoretical case studies include Belleflamme and Vergari (2011) who study an oligopolistic market where firms invest in the acquisition of a new technology that provides an exclusive cost advantage. They find that the relationship between competition and investment is inverted-U shaped. On the contrary, Sacco and Schmutzler (2011) analyse a duopoly model in which an increase in competition is defined as a switch from Cournot to Bertrand competition. They find a U-shaped relationship between competition and investment. Furthermore, Boone (2000) argues that the relationship depends on how a firm's profit is affected by competition according to its initial level of cost efficiency.

These theoretical studies focus on cases where gross profit is higher than investment. Jeanjean (2013) studies the Hotelling model and shows that for high intensity of competition, firms underinvest with respect to the level which would maximise profit. This situation arises because their profit is not sufficient to sustain a profit maximising level of investment. The underinvestment behaviour arises beyond a certain threshold of competition intensity. It is highlighted in the Hotelling framework, but it also shows up in other types of models. ${ }^{8}$ In cases where investment is increasing

\footnotetext{
${ }^{8}$ Annex A.4 provides the threshold above which firms underinvest for different cases studied by Schmutzler (2013).
} 
with competition below the threshold, the overall relationship may be inverted-U shaped due to underinvestment beyond the threshold.

Vives (2008) depart from the use of a single parameter of competition and investigate how specific parameters of competitive pressure such as the number of firms, the magnitude of barriers to entry and the degree of product substitutability affect investment. He shows that the relationship between competition and investment in cost-reducing innovation is negative when competition is parameterised by the number of firms, but positive when it is parameterised by the magnitude of barriers to entry or the degree of product substitutability. Beneito et al. (2015) provide empirical support for these predictions using data from Spanish manufacturing firms. However, this sector-wide analysis may suffer from cross-industry difference in the rate of innovation, as emphasised by Kamien and Schwartz (1975). In addition, given that the relationship depends on the nature of investment and the mode of competition, industry-specific analyses are needed.

Several attempts have been made to uncover the relationship between competition and investment within specific industries. ${ }^{9}$ In the telecommunications industry, most papers have analysed the impact of competition on investment in the fixed broadband market. Cambini and Jiang (2009) review this literature and find that the impact is rather ambiguous. Likewise, Grajek and Roller (2012) find that competition through access regulation negatively affects investment in fixed broadband networks, whereas Bacache et al. (2014) find that access regulation has no effect on new entrants' investment in fixed broadband networks.

In the wireless industry, the empirical investigation of the relationship between competition and investment is still nascent. Most papers assume a linear relationship and find that competition has an ambiguous impact on investment. In particular, Garrone and Zaccagnino (2015) find no correlation between competition and investment in wireless networks. Kang et al. (2012) highlight a positive relationship between market concentration and investment in China's wireless industry. Kim et al. (2011) find a negative relationship between competition, defined as the entry of Mobile Virtual Network Operators (MVNO), and investment by Mobile Network Operators (MNO). Furthermore, Lestage et al. (2013) find that the impact of competition on investment depends on whether the firm is private (negative impact) or state-owned (positive impact).

\footnotetext{
${ }^{9}$ In the automobile industry, Hashmi and Van Biesebroeck (2010) finds a weakly positive relationship between a firm's innovation and its price-cost margin and no relationship at the industry level. In the railways industry, Coublucq et al. (2013) finds that competition lowers investment in the network infrastructure.
} 
Overall, the findings from the literature suffer from some important limitations. First, the speed of adjustment of investment in the wireless networks is still missing from both theoretical and econometric models. The theoretical models discussed above typically considers two-stage games in which firms first invest in cost-reducing technologies and then compete on price or quantity. These models do not distinguish between short and long run effects of competition on investment. Second, theoretical and econometric models implicitly assume a linear relationship between competition and investment. Yet, the ambiguity of the theoretical predictions and empirical findings may stem from a nonlinear relationship between competition and investment. Finally, most empirical papers do not address the endogeneity of competition probably due to the lack of good quality data from which instruments can be derived.

\section{Background on competition and investment in the wireless industry}

This section provides some background information to motivate the analysis of the effect of competition on investment in the wireless industry. It starts with an overview of the policy debate and then emphasises the significance of innovation in the wireless industry due to a strong rate of technological progress.

\subsection{The policy debate on the relationship between competition and investment in the wireless industry}

The policy debate about the relationship between competition and investment in the wireless industry arises in the context of merger and entry waves worldwide and particularly in the European Union. Recently, some national regulators have granted spectrum licenses to new entrants like Free Mobile in France in 2012. Others have cleared proposed mergers particularly in the European Union where recent cases involve Orange and 3G in Austria in 2012, E-Plus and Telefonica in Germany in 2014, Orange and T-Mobile in The Netherlands in 2007, $\mathrm{O}_{2}$ Ireland and $\mathrm{H} 3 \mathrm{G}$ in Ireland in 2014. Meanwhile, some proposed mergers have been challenged like in the case of TeliaSonera and Telenor in Denmark in 2015, and AT\&T and T-Mobile in the United States of America (USA) in 2011. 
These decisions partly reflect the view of the regulators about the market structure that would lower prices and raise investment in the wireless industry. To the extent that competition typically leads to lower price, the debate hinges on the nature of the relationship between competition and investment and more specifically whether investment falls with competition. The answer to this question would guide the regulator in deciding when an entry is more desirable than a merger, and inversely. Yet, there is no consensus about the shape of the relationship.

As a matter of fact, a recent report by the OECD argues that more competition, through more wireless operators, lowers prices and increases the quality of wireless services (OECD, 2014). In the USA, the Department of Justice (DoJ) considers that the wireless market is not competitive enough to require consolidation. It thus challenged the proposed merger between AT\&T and T-Mobile in 2011 (DoJ, 2011).

Unlike these positions, Faulhaber et al. (2011) argue that the USA wireless market is effectively competitive and that market structure, measured by the HerfindahlHirschman index, is not correlated with monthly bills. More recently, a report by the Centre on Regulation in Europe suggests that market consolidation increases prices, but it also raises investment in wireless networks (Genakos et al., 2015). Thus, the policy debate about the effect of competition on investment remains open.

\subsection{Technological progress as a driver of investment in the wireless industry}

The literature on the relationship between competition and innovation applies to innovative markets such as the wireless industry. Indeed, this industry experiences a significant rate of technological progress which drives regular investment in the adoption of new technologies. According to the estimates by Koh and Magee (2006) and Koh and Magee (2008), the rate of technological progress in the information technologies typically surpasses that of other sectors such as the energy industry.

Investment in wireless networks is driven by the new products that equipment manufacturers release every year. These new products can bring about a radical change in the provision of wireless communications services or simply an improvement in the transmission of communication traffic over the network. Radical innovations are characterised by a shift in data transmission speeds or protocols. Over the last two decades, there have been four overlapping generations of mobile telecommunications networks (1G, 2G, $3 \mathrm{G}$ and $4 \mathrm{G}$ ), with several variants in between. The overall 
outcome is a continual enhancement of performances of wireless networks.

The rate of technological progress is even greater for wireless data. Amaya and Magee (2008) estimate an exponential rate of technological progress for wireless data transportation of around 50 per cent since 1970. This corresponds to download speeds doubling almost every year, at the same cost. ${ }^{10}$ Thus current investment affects subsequent investment through its effect on marginal cost. Therefore, investment should be analysed with a dynamic model in order to disentangle between short run and long run effect of competition on investment.

\section{Dataset and variables}

\subsection{Dataset}

The dataset is built by assembling information from four databases: the World Cellular Information Services (WCIS) from Ovum, the GSMA Intelligence database, the online International Telecommunications Union (ITU) database, and the World Development Indicators (WDI) database managed by the World Bank.

The WCIS database provides quarterly accounting information on wireless operators' revenues, subscribers, profits and capital expenditures (CAPEX). The GSMA database provides information on operators' characteristics, namely, their year of entry and whether or not they host MVNO. The WCIS and the GSMA databases are proprietary, but widely used in academic research as in Whalley and Curwen (2014), Kim et al. (2011) and Hazlett et al. (2014). The ITU database provides yearly information on the penetration rate of fixed telephony. Finally, the WDI database contains yearly information on market characteristics such as population density and working-age population (ages 15 to 64 ).

Information retrieved from these four sources has been assembled to obtain an unbalanced panel of 110 wireless operators observed over 25.2 quarters on average, from the first quarter of 2005 to the last quarter of 2012. The final sample is made of 2770 observations. Most of the missing observations are concentrated in the earlier periods. They are due to smaller sized wireless operators not disclosing their accounting figures as they are not listed on the stock market. Very few are due to entry or exit. Table 3 in the appendix provides more details about the sources of

\footnotetext{
${ }^{10}$ With $50 \%$ exponential rate of progress, download speeds double every 1.4 year $\left(\frac{\ln (2)}{0.5}\right)$.
} 
data used in this paper.

\subsection{Variables}

The definitions of the main variables follow:

- Dependent variables: Investment in network infrastructure

Investment in network infrastructure is measured using two variables: the logarithm of CAPEX, and the CAPEX per subscriber. The CAPEX includes expenditures on the acquisition of tangible assets, maintenance of the existing tangible assets with a useful lifetime that extends beyond the fiscal year, and license fees. It also includes spectrum license fees. A dummy variable will be included in the econometric model to account for license fees.

— Policy variables: competition intensity

Competition intensity is calculated on the basis of the Lerner index of monopoly power at the firm level. ${ }^{11}$ It can be expressed as:

$$
\Theta_{i}=1-\frac{P_{i}-c_{i}}{P_{i}}
$$

$\Theta_{i}$ denotes the competition intensity experienced by firm $i$. Calculating competition intensity requires information on price $\left(P_{i}\right)$ and marginal cost $\left(c_{i}\right)$ per minute of voice and per megabyte of wireless data. However, these variables are not observed. Under the assumptions of homogenous good and constant marginal cost of production, the ratio of a firm's operating profit to its total revenue is a valid approximation of the Lerner index of market power. ${ }^{12}$ Therefore, the competition intensity is calculated as:

\footnotetext{
${ }^{11}$ This ratio is generally used in empirical papers on competition. See for instance Aghion et al. (2005) in a general equilibrium setting and Hashmi and Van Biesebroeck (2010) in the automobile industry.

${ }^{12}$ Another issue analysed by Boone (2008) is whether the Lerner index actually measures the intensity of competition. His analyses emphasise that the Lerner index may not be decreasing with the intensity of competition. He proposes the elasticity of profit with respect to marginal cost as an alternative and much more robust way of measuring competition. Empirically, this elasticity can be estimated by regressing the logarithm of profit over the logarithm of cost across the firms within a given market. However, with less than five wireless operators per market, this elasticity cannot be estimated.
} 


$$
\Theta_{i}=1-\frac{\text { Ebitd }_{i}}{\text { Revenue }_{i}}
$$

$E b i t d a_{i}$, the operating profit, is measured using earnings before interest, tax, depreciation and amortisation (EBITDA). It is the difference between total revenues and operating expenditures, excluding portions arising through tax, interest payment, depreciation and amortisation of assets. Revenue $i_{i}$ is the sum of revenue generated through the provision of wireless communications services and the revenue generated from the sales of mobile devices or other equipment sold by the operator during a quarter. Revenue from the provision of wireless communications services includes revenue from voice and data services over the wireless networks, roaming charges, revenue from international direct dialling and interconnection revenue.

口 Instruments and control variables:

As further discussed in section 5.3 on identification strategy, the lagged values of competition intensity and the year of entry into the market are the two instruments for competition intensity.

The estimation controls for potential market size and network deployment costs using respectively the logarithm of working-age population and population density as proxies. The number of subscribers is used in the robustness analysis as an alternative proxy for market size as it is potentially endogenous. For simplicity, we refer to the working-age population as a proxy for market size in the remainder of the paper. The penetration rate of fixed telephony is used as a proxy for competition from fixed lines markets. The penetration rate of fixed telephony is more exogenous than the penetration rate of fixed broadband, a more recent technology whose diffusion may be influenced by investment in wireless networks. The estimation also controls for firms' characteristics by building a dummy variable characterising a wireless operator which hosts MVNO. Additional controls include market and quarter dummies as well as a dummy variable for wireless operators that purchase a frequency license during a given year. This latter is intended to retrieve spectrum license fees from total capital expenditures.

Table 1 below displays summary statistics of the main variables. The list of countries is provided in table 4 in the appendix. 
Table 1: Summary statistics

\begin{tabular}{lrrrrr} 
Variable & Observations & Mean & Std. Deviation & Min & Max \\
\hline Log of CAPEX & 2770 & 3.94 & 1.51 & -1.11 & 7.62 \\
Capex per subscriber & 2770 & 10.11 & 7.63 & 0.15 & 39.73 \\
1-Lerner & 2770 & 0.59 & 0.12 & 0.19 & 1.00 \\
Log. Working-age Pop. & 2770 & 16.53 & 1.43 & 12.93 & 19.16 \\
Log. Pop. Density & 2770 & 4.47 & 1.33 & 0.99 & 8.93 \\
Household penetration of & & & & & \\
fixed telephony & 2770 & 31.94 & 18.64 & 0.25 & 69.51 \\
Host an MVNO & 2770 & 0.65 & 0.48 & 0 & 1 \\
Year of entry & 2770 & 1995.1 & 5.08 & 1979 & 2005 \\
Purchase a license & 2770 & 0.16 & 0.37 & 0 & 1 \\
\hline
\end{tabular}

\section{Empirical methodology}

Given that the theoretical literature does not provide any clear prediction for the relationship between competition and investment in wireless networks, this paper starts by assuming a flexible relationship as expressed in the following equation:

$$
Y_{i q}=f\left(\Theta_{i q}\right)+\nu_{i q}
$$

Where $Y_{i q}$ denotes investment by firm $i$ during quarter $q$. $\Theta_{i q}$ denotes the intensity of competition experienced by firm $i$ during quarter $q . f($.$) is a function that$ characterises the relationship between competition and investment.

The estimation of the relationship between competition and investment proceeds in two steps. In the first step, the nature of the relationship between competition and investment is identified using a non-parametric identification strategy. This strategy does not estimate the parameters of the function $f$, but it is useful for identifying the best functional specification of an econometric model without making any a priori assumption about the relationship between the variables of the model. In the second step, parameters of the function $f$ have been estimated using instrumental variable strategy. 


\section{$5.1 \quad$ Non-parametric identification of the relationship between competition and investment}

Market size is an exogenous determinant of demand for wireless services and, therefore, of operators' investment. As a result, it is included in equation (1). The new equation writes:

$$
Y_{i q}=f\left(\Theta_{i q}\right)+\alpha S_{j q}+\mu_{i q}
$$

$S_{j q}$ denotes the size of market $j$ and $\mu_{i q}$ corresponds to the residuals of the model. Under the assumption that $f$ is linear in its parameters and using the Frish-Waugh Theorem (Frisch and Waugh, 1933), equation (2) can be written as:

$$
Y_{i q}^{r}=f\left(\Theta_{i q}^{r}\right)+\mu_{i q}
$$

Where $Y_{i q}^{r}$ and $\Theta_{i q}^{r}$ are the residuals of the Ordinary Least Squares (OLS) regression of investment and competition on market size. The locally weighted scatterplot smoothing (Lowess), a non-parametric algorithm proposed by Cleveland (1979), is implemented on the set of data points $\left(Y_{k}^{r}, \Theta_{k}^{r}\right)$ to determine the nature of $f$. The integer $k$ is an index that ranks the observations on competition intensity in ascending order.

For a given competition intensity $\Theta_{k}^{r}$, let's define a bandwidth $b$ around this point. This bandwidth determines a subset of pairs $\left(Y_{l}^{r}, \Theta_{l}^{r}\right)$ such that $\Theta_{k-\frac{b}{2}}^{r} \leq \Theta_{l}^{r} \leq \Theta_{k+\frac{b}{2}}^{r}$. The corresponding Lowess smoother of the investment $Y_{k}^{r}$ is the predicted value of the following weighted OLS regression:

$$
Y_{l}^{r}=\beta * w_{l} * \Theta_{l}^{r}+\mu_{l}
$$

$l \in\left[k-\frac{b}{2} ; k+\frac{b}{2}\right]$

$w_{l}$ is a weight attached to the observations indexed by $l$. Several kernel weighting functions can be used. The non-parametric smoothing relies in particular on the tricube weighting function, a robust kernel widely used in the literature on nonparametric modelling. ${ }^{13}$

\footnotetext{
${ }^{13}$ The tricube weighting function is defined as follows:
} 
The Lowess smoother of investment associated with the intensity of competition $\Theta_{k}^{r}$ is determined as:

$$
\hat{Y}_{k}^{r}=\hat{\beta} * w_{l} * \Theta_{k}^{r}
$$

The same procedure is replicated for all $k$, that is, for all observations of the intensity of competition. The Lowess smoother is a graphical representation of the set of points $\left(\hat{Y}_{k}^{r}, \Theta_{k}^{r}\right)$. Fig. 1 below presents the Lowess smoother. It highlights an inverted-U relationship between competition and investment.

Figure 1: Non-parametric curve between competition and investment

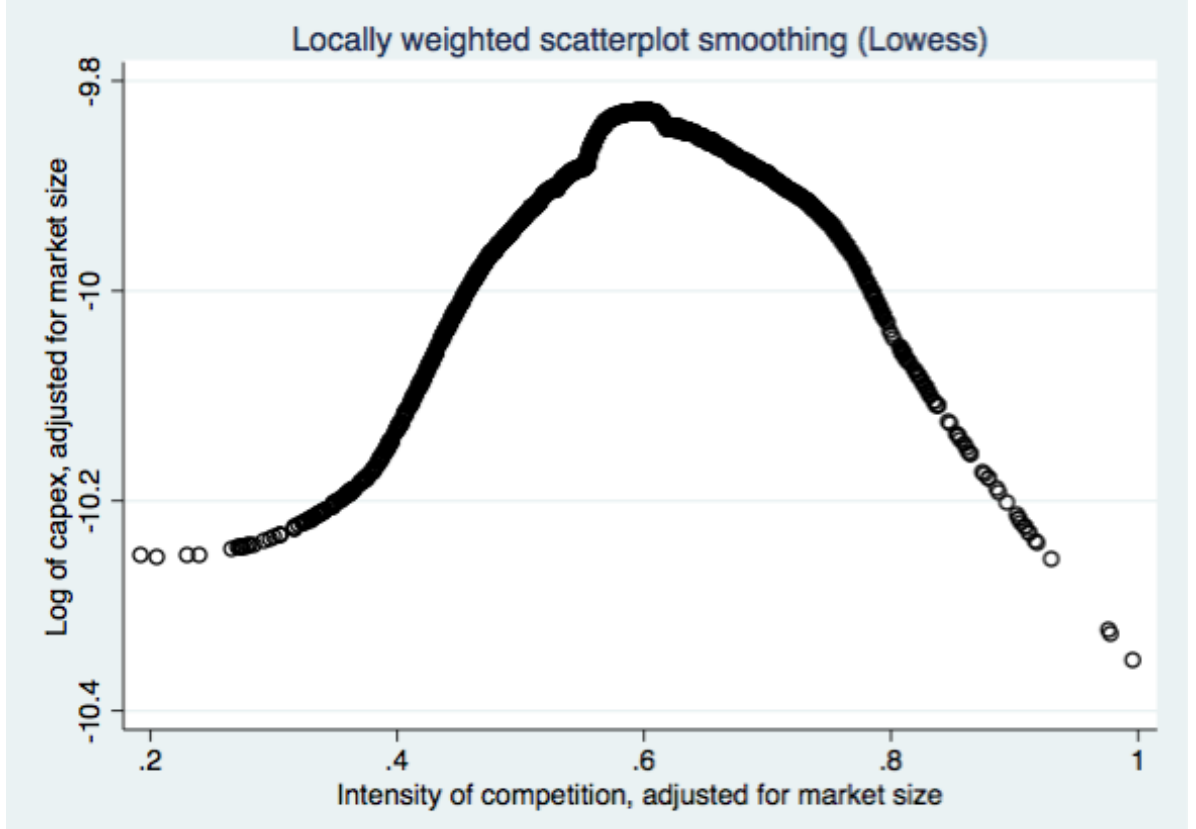

\section{$5.2 \quad$ Econometric model}

The non-parametric relationship between competition and investment identified from the section 5.1 lends support to a quadratic specification of the econometric model. However, the quadratic form should not be interpreted as a causal relationship due to three main issues: speed of adjustment of investment in wireless networks, omitted variables that jointly determine both competition and investment,

$$
K(u)=\frac{70}{81}\left(1-u^{3}\right)^{3}
$$

For all $u$ such that $|u| \leq 1, u=l-k$. 
and finally reverse causality from investment to competition. The econometric model will address these issues.

As discussed in section 3.2, the strong rate of technological progress in wireless industries means that investment in new wireless technologies significantly reduces marginal cost of production. This dynamic feature of investment can be modelled by assuming that a wireless operator invests $y_{q}$ in quarter $q$ in order to reduce marginal cost of production at quarter $q+1: c_{q+1}=c\left(y_{q}\right)$. As $y_{q}$ depends on current marginal cost of production, the previous assumption implies that $y_{q}=g\left(c_{q}\right)=$ $h\left(y_{q-1}\right)$. Therefore, a contemporaneous shock on investment has a lasting effect on the subsequent level of investment. This dynamic feature will be modelled as a first-order autoregressive process.

In addition, the econometric model controls for potential omitted variables characterising the demand for wireless services and the cost of network deployment. To guarantee the exogeneity of the controls variables, the model includes the logarithm of the working-age population and the population density as proxies for demand and cost side variables. ${ }^{14}$

More formally, the econometric model can be expressed as:

$$
Y_{i q}=\gamma_{0}+\gamma_{1} \Theta_{i q}+\gamma_{2} \Theta_{i q}^{2}+\rho Y_{i q-1}+\gamma X_{i q}+\lambda X_{j q}+\mu_{q}+\mu_{i}+\mu_{i q}
$$

This equation links investment by firm $i$ during quarter $q, Y_{i q}$, to a quadratic function of competition intensity $\Theta_{i q}$, controlling for operators' characteristics $X_{i q}$ and market characteristics $X_{j q}$. Variables $\mu_{q}, \mu_{i}$ and $\mu_{i q}$ correspond to unobserved investment shocks that are respectively quarter-specific, operator-specific and quarterly idiosyncratic. In particular, $\mu_{i q}$ corresponds to the residuals, assumed to be heteroskedastic and autocorrelated.

Given that the panel is unbalanced and that sufficient operator's level instrumental variables are not available, equation (6) cannot be identified with the operators' fixed effects $\mu_{i}$. The sample is an unbalanced panel with several observations missing for some operators. In addition, at least two instruments which vary across operators and quarters are necessary to identify the causal impact of competition on investment at the firm level. Without these instruments, the identification can still be made for a representative wireless operator in a given market. This requires

\footnotetext{
${ }^{14}$ Potential controls such as number of subscribers, penetration rate of smartphones and operators' cash flow are typically endogenous.
} 
the assumption that operators fixed effects are the same within markets. Under this assumption, operators fixed effects can be replaced by markets fixed effects denoted by $\mu_{j}$. The econometric model thus writes:

$$
Y_{i q}=\gamma_{0}+\gamma_{1} \Theta_{i q}+\gamma_{2} \Theta_{i q}^{2}+\rho Y_{i q-1}+\gamma X_{i q}+\lambda X_{j q}+\mu_{q}+\mu_{j}+\mu_{i q}
$$

Coefficients $\gamma_{1}$ and $\gamma_{2}$ characterise the short-run effect of competition on investment. If the inverted-U relationship suggested by the non-parametric curve holds, these coefficients should be statistically significant and respectively positive and negative. The short run effect of competition on investment depends on the initial level of competition intensity. It is expressed as:

$$
\operatorname{SRE}(\Theta)=\frac{d E\left(Y / \Theta, X_{i}, X_{j}\right)}{d \Theta}=\gamma_{1}+2 \gamma_{2} \Theta
$$

The short run effect is positive as long as competition intensity $\Theta$ is lower than the threshold $-\frac{\gamma_{1}}{2 \gamma_{2}}$, and negative otherwise. This threshold corresponds to the investment maximising intensity of competition, denoted by $\hat{\Theta}$ :

$$
\hat{\Theta}=-\frac{\gamma_{1}}{2 \gamma_{2}}
$$

The standard error of $\hat{\Theta}$ is estimated using the delta method. ${ }^{15}$

Coefficient $\rho$ characterises the speed of adjustment of investment. It should be comprised between 0 and 1, reflecting the convergence of the long run effect of competition on investment. The long run effect of competition on investment is determined by dividing the short run effect by $1-\rho:{ }^{16}$

$$
\operatorname{LRE}(\Theta)=\frac{1}{1-\rho}\left[\gamma_{1}+2 \gamma_{2} \Theta\right]=\frac{1}{1-\rho} \operatorname{SRE}(\Theta)
$$

The long run effect of competition on investment is larger than the short run effect

\footnotetext{
${ }^{15}$ The delta method is a way to approximate the variance of a non-linear estimator. It basically linearises the estimator using the Taylor's expansion around the mean of the estimate, and then calculate the variance. See Oehlert (1992) for a detailed presentation of the delta method. An estimation algorithm is developed in Stata by Hole (2007).

${ }^{16}$ The long run effect is determined by summing all the contemporaneous effects over an infinite period. Typically, the impact of competition on investment is $S R E(\Theta)$ at date $t, \rho S R E(\Theta)$ at date $t+1, \rho^{2} S R E(\Theta)$ at date $t+2$, and so on. Thus, the long run effect is: $\sum_{k=0}^{\infty} \rho^{k} S R E(\Theta)=$ $\frac{1}{1-\rho} \operatorname{SRE}(\Theta)$.
} 
as long as $0<\rho<1$, that is, $\frac{1}{1-\rho}>1$. The magnitude of this difference increases with the autocorrelation parameter $\rho$. The investment maximising intensity of competition $\hat{\Theta}$ remains the same in the long run.

OLS estimates of coefficients $\gamma_{1}$ and $\gamma_{2}$ would suffer from a simultaneity bias if both investment and competition are determined simultaneously. ${ }^{17}$ Therefore, competition intensity and its square are potentially endogenous. Typically, more efficient firms, which invest more than their rivals, will have higher price-cost margins and thus experience lower competition intensity. In this case, OLS estimate would suggest a downward sloping relationship between competition and investment. As a result, the investment maximising intensity of competition will be underestimated. Another issue is that in a dynamic model, the lagged dependent variable $Y_{i q-1}$ is endogenous. Therefore, OLS estimate of coefficient $\rho$ will be biased.

\subsection{Causal identification and estimation strategies}

The discussion of the econometric model emphasises two potential sources of estimation bias. The first is related to the endogeneity of the intensity of competition, and the second is related to the endogeneity of the lagged dependent variable. This section presents the identification strategies that will be employed to overcome these biases.

The bias stemming from the endogeneity of the intensity of competition is mitigated using an instrumental variable estimation strategy. Due to the presence of the quadratic term of competition intensity, the estimation relies on two instruments, namely, the two-quarter lagged intensity of competition and the year of entry into the market. In the econometric literature, a lagged variable is a standard and natural instrument for a contemporaneous endogenous variable when the sample includes a time dimension. ${ }^{18}$

From a theoretical perspective, competition and investment in the wireless market can be viewed as a two-stage game in which a regulator first determines the intensity

\footnotetext{
${ }^{17}$ The bias remains in a two-stage model where investment is chosen first, followed by a choice of output or price. In this setting, the first-stage investment has an impact on the intensity of competition through the price and the marginal cost.

${ }^{18}$ See Bond (2002) for example. This paper does not use the one-quarter lagged intensity of competition because the intensity of competition does not change significantly from one quarter to the next. As such, a one-quarter lagged intensity of competition would still affect directly investment. In addition, it is simultaneously determined with the one-quarter lagged investment which is an explanatory variable in the dynamic model.
} 
of competition through parameters such as the number of firms and the year of entry into the market. In the next stage, wireless operators invest and compete on price or quantity. In this framework, a firm's year of entry is given and only affects investment through the intensity of competition. As emphasised by Grajek and Roller (2012), regulatory decisions can be endogenous. For instance, a regulator can choose the year of entry in order to provide an incentive for investment. However, endogenous regulation of the year of entry should not hold in the wireless industry if the regulator does not have perfect information about the operators' production costs. In addition, two wireless operators may enter into an identical market at different dates due to the randomness of administrative processes.

Regarding the endogeneity of the lagged dependent variable $\left(Y_{i q-1}\right)$, Bond (2002) reviews the literature on dynamic panel models and suggests estimating model (7) in first-difference using the lags of the dependent variables as instruments. However, the unbalanced nature of the panel data does not allow this identification strategy. Nickell (1981) shows that the coefficient $\rho$ is underestimated by OLS estimation of model (7) including the market-specific fixed effects (FE). On the contrary, $\rho$ is overestimated when model (7) is estimated by OLS without the market-specific fixed effects (Pooled). Therefore, fixed effects and pooled estimates provide lower and upper bounds to the true coefficients. The paper provides both estimates using two and three-quarters lagged variables $\left(Y_{i q-2}\right.$ and $\left.Y_{i q-3}\right)$ as instruments for $Y_{i q-1}$.

The econometric model (7) is estimated using two definitions of investment, namely, the natural logarithm of capital expenditures and capital expenditures per subscriber. Using the natural logarithm has the advantage of providing a better fit and more precise estimates as the variance of the residuals is smaller with the logarithm. ${ }^{19}$ Regarding the capital expenditures per subscriber, it accounts for the size of the operator. Typically, an operator's investment may change with competition due to a net loss or gain of customers.

The model is estimated using both OLS and the Generalized Method of Moment (IV-GMM) estimators. ${ }^{20}$ All estimations correct for arbitrary heteroskedasticity and autocorrelation using the Bartlett Kernel of bandwidth 4 in order to maximise the efficiency of the estimates. ${ }^{21}$ The Kelibergen-Paap Wald rank F-statistics have

\footnotetext{
${ }^{19}$ The R-squared of the model is greater with logarithm than without: 0.87 vs. 0.85 respectively.

${ }^{20}$ The GMM estimator is better than the two-stage least square estimator in correcting for the heteroskedasticity and autocorrelation of the residuals. See Hansen (1982) for the asymptotic properties of the GMM estimator.

${ }^{21}$ The Bartlett Kernel is a weighting function used to estimate the asymptotic covariance matrix of the moment conditions. The bandwidth minus one represents the number of time lags used to compute the asymptotic covariance matrix. A bandwidth of 4 corresponds to three lags used
} 
been compared to the critical values tabulated by Stock and Yogo (2002) to test the weakness of the instruments. Moreover, with more instruments than endogenous variables, the Hansen $J$ test of over-identification is implemented in order to check the validity of the exclusion restriction assumptions, that is, the exogeneity of the instruments. $^{22}$

\section{Results}

\subsection{Main findings: An inverted-U relationship between com- petition and investment}

Table 2 below presents three outcomes of the estimation of the relationship between competition and investment in wireless networks. The first two outcomes are respectively the OLS and IV-GMM estimates of model (7) using the logarithm of capital expenditures as a measure of investment. The third outcome relies on IVGMM estimator but rather uses capital expenditures per subscriber as a measure of investment. For each outcome, table 2 presents both the results of the econometric model with and without market-fixed effects (FE and Pooled respectively). Two main findings emerge from this table.

First, there is an inverted-U relationship between competition and investment in wireless networks. This relationship holds irrespective of the measure of investment, the estimators (OLS or IV-GMM) and the econometric model (Pooled or Fixed effects). It provides a statistical support to the non-parametric finding of an inverted-U shaped relationship. The coefficients of the two competition variables have the expected signs and are significant at 5 or 10 per cent level. The investment maximising intensity of competition $\hat{\Theta}$ is lower for the OLS estimates such that the relationship is almost downward sloping. This suggests that an OLS estimator underestimates the level of competition intensity that maximises investment, due to reverse causality. As discussed in section 5.3, reverse causality may be explained by more efficient firms investing more and experiencing less competition. This may explain why Kang et al. (2012), who do not correct for endogeneity, find a negative

in the estimation in order to correct for autocorrelation. See Baum et al. (2007) for a detailed explanation of the GMM estimator along with the statistical corrections and tests.

${ }^{22}$ The null hypothesis of the Hansen $\mathrm{J}$ test states that all instruments, taken together, are not correlated with the residuals. More formally, this assumption writes: $E(Z \mu)=0$, where $Z$ is a matrix of instruments and $\mu$ denotes the residuals. 
relationship between competition and investment in wireless networks.

Correcting for endogeneity yields an investment maximising intensity of competition between 57 and 65 per cent, depending on the measure of investment: 59 or 60 per cent when investment is measured by the logarithm of capital expenditures, and 61 or 63 per cent when investment is measured by capital expenditures per subscriber. Therefore, as long as the intensity of competition remains below 57 per cent, an increase in the intensity of competition raises investment. Above 65 per cent, a further increase in competition reduces investment.

Second, there is a significant long run effect of competition on investment. The coefficient of the lagged dependent variable is statistically significant in all regressions and comprised between 0 and 1 as expected. In comparison to the magnitude of the short run effect, the long run effect is 4 or 17 times larger, when investment is measured as the logarithm of capital expenditures, and 3 or 8 times larger, when investment is measured by capital expenditures per subscriber. ${ }^{23}$

As predicted by Nickell (1981), the speed of adjustment of investment tends to be overestimated by the pooled model, but underestimated by the fixed effects model. In addition, the investment maximising intensity of competition is much higher for the fixed effects model than for the pooled model. Therefore, a conservative approach would focus on the outcome of the fixed effects model. In consequence, the investment maximising intensity of competition stands at 60 or 63 percent depending on whether or not capital expenditures are normalised by the number of subscribers. Respectively, the magnitude of the long run effect is 3 or 4 times larger than the magnitude of the short run effect.

Regarding the controls variables, it turns out that investment is positively affected by market size, but negatively affected by the cost of network deployment. When market fixed effects are included in the regression, countries surfaces are fixed and a variation in density corresponds to a proportional variation in population. Therefore, working-age population is removed from specifications with market fixed effects. It turns out that the coefficient of population density is positive, which reflects a positive effect of market size on investment.

Competition from fixed line markets, as measured by the penetration rate of fixed telephony, is positively correlated with investment in wireless networks. However, this correlation is no longer significant when market fixed effects are included in the

\footnotetext{
${ }^{23}$ The magnitude of the difference between the short and long run effects is calculated as: $\frac{1}{1-\rho}$, where $\rho$ is the first-order autoregressive coefficient.
} 
regression. This variable is not significant in the other regressions and has been removed to obtain more precise estimates.

The regression also controls for whether or not a wireless operator hosts an MVNO. The estimates suggest that wireless operators which host an MVNO invest more than their rivals. This superior investment reflects the additional expenditures needed to provide upstream network access to the downstream MVNO. The control for licenses fees is not significant as frequency bands are not so frequently released and variations in investment due to licence fees are subsumed into the residuals as measurement errors. Estimates of quarterly fixed effects not reported here suggest a yearly seasonality such that investment in wireless networks rises every year from the first to the last quarter.

Finally, all tests statistics support the significance of the model and estimates. The R-squared of the OLS estimates is larger than 85 per cent, suggesting that the econometric model accounts for most of the determinants of investment in wireless networks. The Ficher test confirms the overall significance of all regressions. Regarding the IV-GMM estimates, the under-identification test rejects the null hypothesis that the instruments are not correlated with the endogenous variables. In addition, the p-values of the Hansen's over-identification tests are all greater than 10 per cent, implying that the null hypothesis of exogeneity of the instruments cannot be rejected. 
Table 2: The impact of competition on investment in wireless networks

\begin{tabular}{|c|c|c|c|c|c|c|}
\hline Dependent variable: & \multicolumn{4}{|c|}{ Logarithm of CAPEX (investment) } & \multirow{2}{*}{\multicolumn{2}{|c|}{$\begin{array}{c}\text { Capex per subscriber } \\
\text { IV-GMM }\end{array}$}} \\
\hline Estimator: & \multicolumn{2}{|c|}{ OLS } & \multicolumn{2}{|c|}{ IV-GMM } & & \\
\hline Model & Pooled & FE & Pooled & $\mathrm{FE}$ & Pooled & $\mathrm{FE}$ \\
\hline Specification & (1) & (2) & (3) & (4) & $(5)$ & (6) \\
\hline \multirow[t]{2}{*}{ 1-Lerner } & 0.86 & 0.95 & $5.02^{*}$ & $19.13^{* *}$ & $89.77^{* *}$ & $161.27^{*}$ \\
\hline & $(0.67)$ & $(0.75)$ & (3.04) & $(9.23)$ & $(37.11)$ & $(93.18)$ \\
\hline \multirow[t]{2}{*}{$(1-\text {-Lerner })^{\wedge} 2$} & $-1.08^{*}$ & $-1.19^{*}$ & $-4.22^{*}$ & $-15.88^{* *}$ & $-73.77^{\star *}$ & $-128.30^{*}$ \\
\hline & $(0.57)$ & $(0.63)$ & $(2.56)$ & (7.51) & (31.33) & (75.68) \\
\hline \multirow[t]{2}{*}{$Y_{-}(t-1)$} & $0.63^{* \star *}$ & $0.38^{* * *}$ & $0.94^{* * *}$ & $0.75^{* * *}$ & $0.88^{* * *}$ & $0.72^{* * *}$ \\
\hline & $(0.02)$ & $(0.03)$ & $(0.02)$ & $(0.06)$ & $(0.03)$ & $(0.06)$ \\
\hline \multirow[t]{2}{*}{ Log of working-age population } & $0.33^{* * *}$ & & $0.05^{\star \star *}$ & & 0.09 & \\
\hline & $(0.02)$ & & $(0.02)$ & & $(0.07)$ & \\
\hline \multirow[t]{2}{*}{ Log of population density } & $-0.02^{* *}$ & $2.13^{* * *}$ & -0.00 & $1.05^{*}$ & -0.03 & -0.54 \\
\hline & $(0.01)$ & $(0.50)$ & $(0.01)$ & $(0.57)$ & $(0.07)$ & $(5.41)$ \\
\hline \multirow[t]{2}{*}{ Fixed telephony penetration } & $0.01^{* * *}$ & 0.00 & & & & \\
\hline & $(0.00)$ & $(0.00)$ & & & & \\
\hline \multirow[t]{2}{*}{ Hosting MVNO } & $0.09^{* * *}$ & $0.17^{* * *}$ & -0.02 & $0.09^{*}$ & -0.39 & 0.21 \\
\hline & $(0.03)$ & $(0.06)$ & $(0.02)$ & $(0.05)$ & $(0.30)$ & $(0.38)$ \\
\hline \multirow[t]{2}{*}{ Having purchased a license } & -0.00 & 0.01 & -0.00 & 0.01 & -0.12 & -0.11 \\
\hline & $(0.03)$ & $(0.03)$ & $(0.03)$ & $(0.03)$ & $(0.40)$ & $(0.41)$ \\
\hline Quarter fixed effects & $\checkmark$ & $\checkmark$ & $\checkmark$ & $\checkmark$ & $\checkmark$ & $\checkmark$ \\
\hline Market fixed effects & & $\checkmark$ & & $\checkmark$ & & $\checkmark$ \\
\hline \multirow[t]{2}{*}{ Constant } & $-4.01^{* * *}$ & $-4.44^{\star *}$ & -1.67 & $-7.45^{\star \star \star}$ & $-23.69^{* *}$ & -36.91 \\
\hline & $(0.37)$ & $(1.76)$ & $(1.03)$ & $(2.81)$ & $(11.15)$ & $(26.96)$ \\
\hline Observations & 2,770 & 2,770 & 2,586 & 2,586 & 2,595 & 2,595 \\
\hline R-squared & 0.864 & 0.887 & & & & \\
\hline F-Statistic & 519.9 & 248.1 & 1029.6 & 323.57 & 88.97 & 53.31 \\
\hline \multicolumn{7}{|c|}{ Investment Maximizing Intensity of Competition: (\%) } \\
\hline Lower bound & 19 & 18 & 57 & 58 & 59 & 60 \\
\hline Estimate & 40 & 40 & 59 & 60 & 61 & 63 \\
\hline Upper bound & 61 & 62 & 62 & 63 & 63 & 65 \\
\hline \multicolumn{7}{|c|}{ Under-identification test ( $\mathrm{HO}$ : the instruments do not significantly affect the intensity of competition) } \\
\hline \multirow{2}{*}{\multicolumn{3}{|c|}{$\begin{array}{l}\text { LM statistic } \\
\text { Weak instruments test ( } \mathrm{HO} \text { : instruments are weak) }\end{array}$}} & 30.4 & 10.5 & 40.1 & 15.0 \\
\hline & & & & & & \\
\hline \multicolumn{3}{|c|}{ Wald F statistic } & 18.0 & 3.64 & 21.1 & 4.92 \\
\hline \multicolumn{3}{|c|}{ J-Hansen overidentification test ( $p$-value) } & 0.24 & 0.33 & 0.95 & 0.96 \\
\hline
\end{tabular}

Note: Significant at 1\%(***), 5\% (**) and $10 \%\left({ }^{*}\right)$. Standard errors robust to arbitrary heteroskedasticity and autocorrelation are in parentheses. (1 - Lerner) represents the intensity of competition. $Y_{-}(t-1)$ refers to the one-quarter lagged of the dependent variable. CAPEX stands for capital expenditures. The instrumental variables estimates based on the generalised method of moments estimators (IV-GMM) use the two-quarters lagged intensity of competition, and the year of a firm's entry into the market a instruments for the contemporaneous intensity of competition. Two and three-quarters lagged of the dependent variable is used as instruments for the one-quarter lagged explanatory variable $Y_{-}(t-1)$. The Lagrangian Multiplier $(L M)$ statistic of under-identification is greater than its critical value, meaning that the instruments are good at predicting the intensity of competition. 


\subsection{Robustness checks}

This section presents the outcome of the first-stage instrumental variable estimation procedure. It also discusses the outcomes of the estimation when operators' fixed effects are substituted for market fixed effects, the performance of the model with linear specification, as well as the use of the number of subscribers as a proxy for market size.

- Correlation of the instruments with the endogenous variables

The first three columns of table 5 in the appendix present the first-stage estimates of the main specification in column (4) of table 2. This specification corresponds to the IV-GMM estimation of the econometric model (7) with market fixed effects. As expected, the two-quarter lagged intensity of competition as well as the year of entry into the market have positive and significant effect on competition intensity. The one-quarter lagged investment is significantly affected by all four instruments. It is negatively affected by the two instruments for competition and positively by the two and three-quarters lagged investment. These correlations are in line with the outcome of the under-identification test which rejects the hypothesis that the instruments are not significant determinants of the endogenous variables.

- Introducing operators fixed effects

Column (4) of table 5 in the appendix displays the OLS estimate of the econometric model (6), that is, when operators fixed effects are included in the model. It turns out that the relationship between competition and investment is still inverted-U, but the estimates are no longer significant. The investment maximising intensity of competition stands at 63 per cent, closer to the level found with the market fixed effects. This paper does not address the endogeneity issue when operators fixed effects are included since this identification requires at least two instruments which vary across operators and quarters. Using two lagged variables of the intensity of competition as instruments fail to pass the under-identification, the weak instrument and the over-identification tests.

- Linear specification of the relationship between competition and investment

Columns (5) and (6) of table 5 in the appendix present respectively the OLS and IV estimates of the relationship between competition and investment using a linear specification. The OLS estimate yields a negative and significant relationship between competition and investment consistently with the outcome of the estimation with 
a quadratic specification. The investment maximising intensity of competition was found at a very low level of the intensity of competition, 40 per cent more precisely.

However, the effect of competition on investment is no longer significant when endogeneity is accounted for in column (6). The instruments are the two-quarter lagged intensity of competition and the two and three-quarters lagged investment. This result contrasts with the significant effect of competition that emerges when a quadratic specification is estimated. It provides a further support for the non-monotone and inverted-U shaped relationship suggested by the non-parametric curve.

- Number of subscribers as a proxy for market size

Column (7) of table 5 in the appendix presents the IV estimates of the relationship between competition and investment using the total number of subscribers as a proxy for market size in replacement of the working-age population. The inverted-U still holds, but it is no longer significant.

\subsection{Discussion and policy implications}

A number of insights provided by the specificity of the wireless industry lend support to an inverted-U shaped relationship between competition and investment. As indicated in the literature review, the inverted- $U$ shaped relationship may stem from the combination of two effects: The escape-competition effect whereby competition increases investment and the efficiency effect whereby competition reduces investment. In the case of the wireless industry, the escape-competition effect is weaker with intense competition because operators have the opportunity to buy the same equipment from manufacturers at the same time.

In fact, innovation in wireless infrastructure is mainly designed by equipment manufacturers which provide their facilities to all rival operators at the same time. Opportunities to escape competition by investment are, therefore, temporary, in particular when competition is intense. When only one rival has the opportunity to invest, as highlighted by Arrow (1962) in the case of a symmetric duopoly, investment allows it to gain a longer lasting monopoly power and thus escape competition. However, if both firms invest, neither of them durably succeeds in escaping competition.

While the theoretical framework provided by Schmutzler (2013) is consistent with the wireless industry, as it allows firms to invest simultaneously, the examples which illustrate this framework do not show an inverted-U relationship. This may be 
because the framework only focuses on cases where profit (gross profit minus investment) is positive. In the case of a symmetric duopoly, firms invest expecting to increase their profit. They choose the amount of investment that maximises their profit. Both firms invest the same amount because of the symmetry and therefore cannot escape competition nor increase their profit. It is possible that their gross profit is lower than their profit maximising investment. In that case, they cannot invest the profit maximising amount because they do not have it and cannot expect to earn it. Then firms change their behaviour by limiting their investments so that their profit is nil (Jeanjean, 2013). In this case, investments, like gross profits, tend to decrease with competition.

Whatever the shape of the relationship for low levels of competition, investment decreases since competition intensity is higher than the level at which profits are nil. As a result, when the relationship is increasing for lower intensity of competition it becomes decreasing for higher intensity. ${ }^{24}$ The magnitude of the impact of investment on quality or cost reduction increases the probability that this change in firms' behaviour will occur. Appendix A.4 shows, using Schmutzler's examples, that a decrease in the cost of investment tends to reduce the threshold of competition intensity at which profit is nil. As a result, increasing competition beyond this threshold pushes operators to reduce their investment to offset the decline in gross profit. As highlighted in section 3, the wireless industry is characterised by a very high rate of technological progress. This means that the cost of each additional megabyte is decreasing and the impact of investment on cost reduction is correspondingly very significant. It is, therefore, not surprising that competition has a negative impact on investment when competition is very intense.

The inverted-U relationship suggests that policymakers should consider wireless operators' profit margins, that is, the ratio of EBITDA to revenue, before allowing a new market entrant or merger in the industry. The inverted-U shaped means that there is an intermediate level of profit margin that maximises investment. This does not imply that welfare is maximised at the same level of competition.

However, in the wireless industry, investment drives traffic and the fall in megabyte prices (Jeanjean, 2015). Strong technical progress amplifies the impact of investment on quality as measured by the bit rate offered to consumers. Investment is decisive for traffic growth and megabyte prices drop for consumers. The socially optimal intensity of competition should then be close to the level which maximises investment. Targeting maximum investment thus appears to be a reasonable option

\footnotetext{
${ }^{24}$ Examples E3 and E4 in Schmutzler (2013).
} 
for policymakers.

Another issue is how policymakers should target this level. When profit margins are below the lower bound of the confidence interval (35 per cent), a merger is actually more desirable than a new entrant. On the other hand, when profit margins are well above the upper bound of the confidence interval (42 per cent), a new entrant may generate greater incentives to invest than would a merger. When profit margins are between these two thresholds, then merger analysis has to be done on a case-bycase basis. Alternatively, policymakers can adjust profit margin levels by allowing the entry of an MVNO or lowering consumers' switching costs (number portability, changes to the commitment period, etc.). 


\section{Summary and Conclusion}

This paper uses firm level data and an instrumental variable estimation strategy to identify the relationship between competition and investment in the wireless industry. It finds a robust inverted-U relationship between competition intensity and investment, where competition is measured on the basis of the Lerner index and investment by the logarithm of capital expenditures or the capital expenditures per subscriber. The intensity of competition which maximises investment in wireless networks stands at 60 or 63 per cent when investment is respectively measured as capital expenditures or capital expenditures per subscriber. In addition, the estimates suggest a significant long run effect of competition on investment which amplifies the short run effect by a factor of 3 to 4 .

These findings provide empirical evidence on the impact of competition on investment in the wireless industry. They complement the findings of Garrone and Zaccagnino (2015) by focusing specifically on investment in the wireless networks rather than combining investment in fixed and mobile networks. Furthermore, the results of this paper extend those of Kang et al. (2012) by providing a causal estimate of the impact of competition on investment. It also investigates the long run effect of competition on investment. In addition, the geographical scope of this paper is much broader, encompassing cases where investment rises and falls with competition.

The findings of this paper suggest that policymakers should consider wireless operators' profit margin levels before allowing a new entrant or a merger in the wireless industry. When the profit margin is below 35 per cent, a merger may be a better way to raise social surplus than a new entry. On the other hand, when it is above 42 per cent, an additional entrant may increase social surplus more than a merger due to higher incentives to invest. Between these two thresholds, a case-by-case analysis of merger proposals is recommended.

The results of this paper should to be interpreted with caution as they apply to a representative wireless operator in a given market. This is due to the assumption behind the inclusion of market fixed effects instead of operators fixed effects in the econometric model. Further investigations need to identify relevant instrumental variable or identification strategy to account for heterogeneity across wireless operators within a given market. Another limitation is the definition of the dependent variable. A better dependent variable which is much more correlated with consumer surplus is the quality of wireless services. To the extent that more investment in wireless networks does not necessarily translate into higher quality of services, fu- 
ture work needs to examine the relationship between competition and quality in the wireless industry.

Regarding the main explanatory variable, the analysis focuses on the intensity of competition measured on the basis of the Lerner index. However, a much more direct way to influence the intensity of competition is through the market structure and particularly the number of wireless operators. Future research will address how the market structure affects investment incentives and quality and how it depends on asymmetry between firms. Finally, the analysis implicitly assumes that wireless operators compete in the upstream market by investing in their own network. However, network sharing is becoming prevalent. Future works should control for network sharing and investigate its effects on the quality of wireless services. 


\section{References}

Aghion, P., Bloom, N., Blundell, R., Griffith, R., and Howitt, P. (2005). Competition and innovation: An inverted-u relationship. Quaterly Journal of Economics, 120(2):701-728.

Amaya, M. A. and Magee, C. L. (2008). The progress in wireless data transport and its role in the evolving internet. Working papers, Massachusetts Institute of Technology, Engineering Systems Division.

Arrow, K. (1962). Economic welfare and the allocation of ressources for invention. Nber chapters, in: The Rate and Direction of Inventive Activity: Economic and Social Factors, pages 609-626 National Bureau of Economic Research, Inc.

Bacache, M., Bourreau, M., and Gaudin, G. (2014). Dynamic entry and investment in new infrastructures: Empirical evidence from the fixed broadband industry. Review of Industrial Organization, 44:179-209.

Baum, C. F., Schaffer, M. E., and Stillman, S. (2007). Enhanced routines for instrumental variables/Generalized Method of Moments estimation and testing. Stata Journal, 7(4):465-506.

Belleflamme, P. and Vergari, C. (2011). Incentives to innovate in oligopolies. Manchester School, 79:6-28.

Beneito, P., Coscolla-Girona, P., Rochina-Barrachina, M. E., and Sanchis, A. (2015). Competitive pressure and innovation at the firm level. The Journal of Industrial Economics, 63(3).

Blundell, R., Griffith, R., and Van Reenen, J. (1999). Market share, market value and innovation in a panel of british manufacturing firms. The Review of Economic Studies, 66(3):529-554.

Bond, S. (2002). Dynamic panel data models: A guide to micro data methods and practice. Working papers, Institute for Fiscal Studies.

Boone, J. (2000). Competitive pressure: the effects on investments in product and process innovation. RAND Journal of Economics, 31:549-569.

Boone, J. (2008). A new way to measure competition. The Economic Journal, (118):1245-1261. 
Cambini, C. and Jiang, Y. (2009). Broadband investment and regulation: A literature review. Telecommunications Policy, 11:559-574.

Cleveland, W. S. (1979). Robust locally weighted regression and smoothing scatterplots. Journal of the American Statistical Association, 74:829-836.

Coublucq, D., Ivaldi, M., and McCullough, G. (2013). Static-dynamic efficiency trade-off in an open access policy: Application to the US rail freight industry. Working papers.

DoJ (2011). USA DoJ v. ATT Inc. and T-Mobile USA Inc.: Case 1:11-cv-01560. Complaint, US Department of Justice.

Faulhaber, G. R., Hahn, R. W., and Singer, H. J. (2011). Assessing competition in US wireless markets: Review of the FCC's competition reports. SSRN Working Paper, SSRN.

Frisch, W. and Waugh, F. V. (1933). Partial time regressions as compared with individual trends. Econometrica, 1:387-401.

Garrone, P. and Zaccagnino, M. (2015). Seeking the links between competition and telecommunications investments. Telecommunications Policy, 39:388-405.

Genakos, C., Valletti, T., and Verboven, F. (2015). Evaluating market consolidation in mobile communications. Report, CERRE.

Gilbert, R. and Newbery, D. (1982). Preemptive patentive and the persistence of monopoly. American Economic Review, 72:514-526.

Grajek, M. and Roller, L.-H. (2012). Regulation and investment in networks industries: Evidence from european telecoms. Journal of Law and Economics, 55(1):189-216.

Hansen, L. P. (1982). Large sample properties of Generalized Method of Moments estimators. Econometrica, 50(4):1029-1054.

Hashmi, A. R. and Van Biesebroeck, J. (2010). Market structure and innovation: A dynamic analysis of the global automobile industry. Working papers, National Bureau of Economic Research.

Hazlett, T. W., Oh, S., and Skorup, B. (2014). Natural experiments in mobile phone regulation: Estimated effects of prohibiting handset bundling in Finland 
and Belgium. George Mason Law \& Economics Research Paper n 14-17, George Mason University.

Hole, A. R. (2007). WTP: Stata module to estimate the confidence intervals for willingness to pay measures. Software components, Boston College, Department of Economics.

Jeanjean, F. (2013). Incentives to invest in improving quality in the telecommunications industry. Chinese Business Review, 12(4):223-241.

Jeanjean, F. (2015). What causes the megabyte price drop in the mobile industry? Journal of Industrial and Business Economics.

Kamien, Morton, I. and Schwartz, Nancy, L. (1975). Market structure and innovation: A survey. Journal of Economic Literature, 13(1):1-37.

Kang, F., Hauge, J. A., and Lu, T.-J. (2012). Competition and mobile network investment in China's telecommunications industry. Telecommunications Policy, 36(10):901-913.

Kim, J., Kim, Y., Gaston, N., Lestage, R., Kim, Y., and Flacher, D. (2011). Access regulation and infrastructure investment in the mobile telecommunications industry. Telecommunications Policy, 35:907-919.

Koh, H. and Magee, C. L. (2006). A functional approach for studying technological progress: Application to information technology. Technological Forecasting 86 Social Change, 73:1061-1083.

Koh, H. and Magee, C. L. (2008). A functional approach for studying technological progress: Extension to energy technology. Technological Forecasting \& Social Change, 75:735-758.

Kraft, K. (1989). Market structure, firm characteristics and innovative activity. The Journal of Industrial Economics, 37(3):329-336.

Lestage, R., Kim, Y., Kim, J., and Kim, Y. (2013). Competition and investment in telecommunications: Does competition have the same impact on investment by private and state-owned firms? Information Economics and Policy, 25:41-50.

Mathis, J. and Sand-Zantman, W. (2014). Competition and investment: What do we know from the literature? Working papers, IDEI. 
Nickell, S. (1981). Biases in dynamic models with fixed effects. Econometrica, 49:1417-1426.

Nickell, S. J. (1996). Competition and corporate performance. Journal of Political Economy, 104(4):724-746.

OECD (2014). Wireless market structures and network sharing. OECD digital economy papers, OECD.

Oehlert, G. W. (1992). A note on the delta method. The American Statistician, $46: 27-29$.

Sacco, D. and Schmutzler, A. (2011). Is there a U-shaped relation between competition and investment? International Journal of Industrial Organization, 27.

Schmutzler, A. (2013). Competition and investment - a unified approach. International Journal of Industrial Organization, 31:477-487.

Schumpeter, J. (1942). Capitalism, Socialism and Democracy. New York, Harper \& Row edition.

Stock, J. H. and Yogo, M. (2002). Testing for weak instruments in linear IV regression. Nber technical working papers 0284, National Bureau of Economic Research, Inc.

Tang, J. (2006). Competition and innovation behaviour. Research Policy, 35:68-82.

Tirole, J. (1988). The theory of industrial organization. Mit press edition.

Vives, X. (2008). Innovation and competitive pressure. The Journal of Industrial Economics, 56:419-469.

Whalley, J. and Curwen, P. (2014). From global aspirations to regional dominance: The case of Deutsche Telekom. Info, 16:33-53. 


\section{A Appendix}

\section{A.1 Description of the dataset}

Table 3: List of variables used in the estimations

\begin{tabular}{|c|c|c|c|c|}
\hline Original Variables & $\begin{array}{l}\text { Constructed } \\
\text { Variables }\end{array}$ & $\begin{array}{l}\text { Unit of } \\
\text { observation }\end{array}$ & $\begin{array}{l}\text { Time } \\
\text { dimension }\end{array}$ & Data Source \\
\hline Total and service revenues & Revenue & Firm level & quarterly & WCIS, Ovum \\
\hline $\begin{array}{l}\text { Earning Before Interest, Tax, } \\
\text { Depreciation and Amortization } \\
\text { (Ebitda) }\end{array}$ & Profit & Firm level & quarterly & WCIS, Ovum \\
\hline Subscribers & $\begin{array}{l}\text { Capex per } \\
\text { subscriber }\end{array}$ & Firm level & quarterly & WCIS, Ovum \\
\hline $\begin{array}{l}\text { Capital expenditures including } \\
\text { license fees }\end{array}$ & Investment & Firm level & quarterly & WCIS, Ovum \\
\hline Purchase of licenses & $\begin{array}{l}\text { Dummy for license } \\
\text { purchase }\end{array}$ & Firm level & & WCIS, Ovum \\
\hline $\begin{array}{l}\text { Household penetration of fixed } \\
\text { telephony }\end{array}$ & & Market level & yearly & ITU \\
\hline Year of entry & $\begin{array}{l}\text { Year of entry into } \\
\text { the market }\end{array}$ & Firm level & & $\begin{array}{l}\text { Wireless Intelligence, } \\
\text { GSMA }\end{array}$ \\
\hline $\begin{array}{l}\text { Mobile Virtual Network } \\
\text { Operators (MVNO) }\end{array}$ & Hosting an MVNO & Firm level & & $\begin{array}{l}\text { Wireless Intelligence, } \\
\text { GSMA }\end{array}$ \\
\hline $\begin{array}{l}\text { Date of launch of the mobile } \\
\text { network }\end{array}$ & & Firm level & & $\begin{array}{l}\text { Wireless Intelligence, } \\
\text { GSMA }\end{array}$ \\
\hline Population density & $\begin{array}{l}\text { Proxy for cost of } \\
\text { network deployment }\end{array}$ & Market level & yearly & $\begin{array}{l}\text { World Development } \\
\text { Indicator, World Bank } \\
\text { Group }\end{array}$ \\
\hline $\begin{array}{l}\text { Population between } 15 \text { and } 64 \\
\text { years old }\end{array}$ & Market size & Market level & yearly & $\begin{array}{l}\text { World Development } \\
\text { Indicator, World Bank } \\
\text { Group }\end{array}$ \\
\hline
\end{tabular}

Table 4: List of countries within the regions

\begin{tabular}{|c|c|}
\hline Region & Countries \\
\hline Africa & $\begin{array}{l}\text { Algeria, Cameroon, Egypt, Ghana, Kenya, Lesotho, Nigeria, South Africa, Sudan, Tanzania, } \\
\text { Tunisia }\end{array}$ \\
\hline Latin America & Argentina, Brazil, Chile, Ecuador, Mexico, Uruguay, Venezuela \\
\hline Asia Pacific & $\begin{array}{l}\text { Australia, Bangladesh, Hong Kong, Indonesia, Japan, Korea, Malaysia, Pakistan, Singapore, } \\
\text { Thailand }\end{array}$ \\
\hline Eastern Europe & $\begin{array}{l}\text { Armenia, Belarus, Bulgaria, Croatia, Czech Republic, Estonia, Hungary, Kazakhstan, Latvia, } \\
\text { Lithuania, Montenegro, Poland, Russia, Serbia, Slovenia, Ukraine, Uzbekistan }\end{array}$ \\
\hline Western Europe & $\begin{array}{l}\text { Austria, Belgium, Denmark, Finland, France, Germany, Greece, Ireland, Israel, Italy, } \\
\text { Netherlands, Norway, Portugal, Spain, Sweden, Switzerland, Turkey, United Kingdom }\end{array}$ \\
\hline Middle East & Iraq, Jordan, Kuwait, Syria \\
\hline USA/Canada & Canada, USA \\
\hline
\end{tabular}




\section{A.2 Local polynomial smoothing of the relationship between}

competition and investment

Figure 2: Non-parametric curve between competition and investment

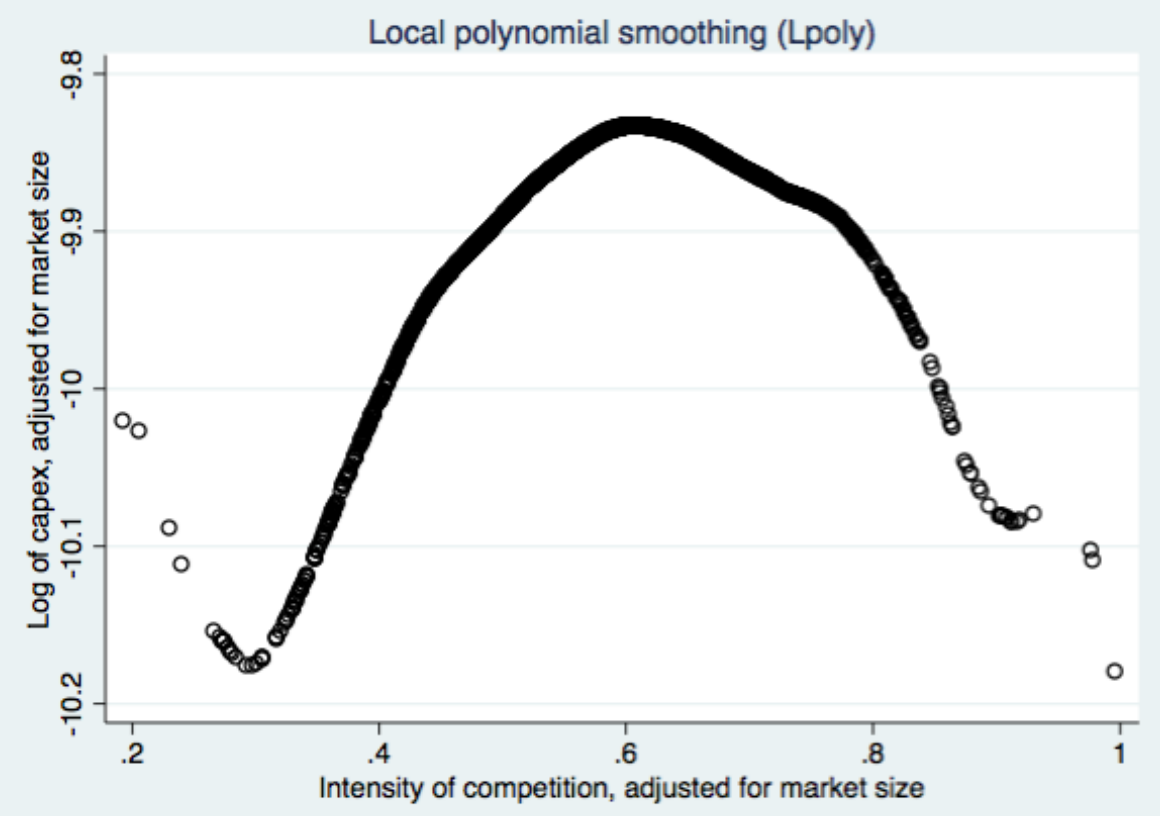




\section{A.3 Robustness Checks}

Table 5: Robustness checks results

\begin{tabular}{|c|c|c|c|c|c|c|c|}
\hline & \multirow{2}{*}{$\begin{array}{c}\text { 1-Lerner } \\
(1)\end{array}$} & \multirow{2}{*}{$\begin{array}{c}(1- \\
\text { Lerner)^2 } \\
(2)\end{array}$} & \multirow{2}{*}{$\begin{array}{c}\underset{\text { logcapex_- }}{(t-1)} \\
(3)\end{array}$} & \multicolumn{4}{|c|}{ Log. of capital expenditures } \\
\hline & & & & (4) & (5) & $(6)$ & (7) \\
\hline \multirow[t]{2}{*}{ 1-Lerner } & & & & 0.332 & $-0.466^{\star \star \star}$ & -0.282 & 3.900 \\
\hline & & & & $(0.817)$ & $(0.127)$ & $(0.229)$ & $(2.668)$ \\
\hline \multirow[t]{2}{*}{$(1 \text {-Lerner })^{\wedge} 2$} & & & & -0.316 & & & -3.301 \\
\hline & & & & $(0.694)$ & & & $(2.253)$ \\
\hline \multirow[t]{2}{*}{ (1-Lerner)_(t-2) } & $0.514^{* * *}$ & $0.625^{\star * *}$ & $-0.453^{* * *}$ & & & & \\
\hline & $(0.027)$ & $(0.034)$ & $(0.138)$ & & & & \\
\hline \multirow[t]{2}{*}{ Year of entry } & $0.004^{\star * *}$ & $0.005^{* * *}$ & $-0.015^{* * *}$ & & & & \\
\hline & $(0.001)$ & $(0.001)$ & $(0.004)$ & & & & \\
\hline \multirow[t]{2}{*}{ logcapex_(t-1) } & & & & $0.316^{* * *}$ & $0.382^{* * *}$ & $0.792^{* * *}$ & $0.943^{* * *}$ \\
\hline & & & & $(0.029)$ & $(0.029)$ & $(0.046)$ & $(0.017)$ \\
\hline \multirow[t]{2}{*}{ logcapex_(t-2) } & -0.003 & -0.004 & $0.307^{* \star *}$ & & & & \\
\hline & $(0.003)$ & $(0.003)$ & $(0.026)$ & & & & \\
\hline \multirow[t]{2}{*}{ logcapex_(t-3) } & -0.003 & -0.004 & $0.171^{* * *}$ & & & & \\
\hline & $(0.002)$ & $(0.003)$ & $(0.026)$ & & & & \\
\hline \multirow[t]{2}{*}{$\begin{array}{l}\text { Log of working-age } \\
\text { population }\end{array}$} & & & & $1.390^{* * *}$ & & & \\
\hline & & & & $(0.401)$ & & & \\
\hline \multirow[t]{2}{*}{ Log of subscribers } & & & & & & & $0.051^{* * *}$ \\
\hline & & & & & & & $(0.018)$ \\
\hline \multirow[t]{2}{*}{$\begin{array}{l}\text { Log of population } \\
\text { density }\end{array}$} & $0.150^{* *}$ & $0.165^{\star *}$ & $1.631^{* * *}$ & $0.173^{* * *}$ & $2.146^{\star \star \star}$ & $1.269^{* \star *}$ & -0.004 \\
\hline & $(0.073)$ & $(0.080)$ & $(0.502)$ & $(0.053)$ & $(0.504)$ & $(0.425)$ & $(0.006)$ \\
\hline Hosting MVNO & -0.001 & 0.001 & $0.169^{* * *}$ & -1.146 & $0.171^{* \star *}$ & 0.056 & -0.031 \\
\hline \multirow{3}{*}{$\begin{array}{l}\text { Having purchased a } \\
\text { license }\end{array}$} & $(0.008)$ & $(0.010)$ & $(0.051)$ & $(1.204)$ & $(0.056)$ & $(0.038)$ & $(0.023)$ \\
\hline & 0.003 & 0.004 & $0.050^{*}$ & -0.003 & 0.010 & -0.004 & 0.001 \\
\hline & $(0.004)$ & $(0.005)$ & $(0.028)$ & $(0.030)$ & $(0.031)$ & $(0.026)$ & $(0.027)$ \\
\hline Quarter fixed effects & $\checkmark$ & $\checkmark$ & $\checkmark$ & $\checkmark$ & $\checkmark$ & $\checkmark$ & $\checkmark$ \\
\hline \multirow{2}{*}{$\begin{array}{l}\text { Market fixed effects } \\
\text { Operator fixed } \\
\text { effects }\end{array}$} & $\checkmark$ & $\checkmark$ & $\checkmark$ & & $\checkmark$ & $\checkmark$ & \\
\hline & & & & $\checkmark$ & & & \\
\hline \multirow[t]{2}{*}{ Constant } & $-7.305^{\star \star \star}$ & $-10.257^{* * *}$ & $26.778^{\star * *}$ & $-20.739^{\star \star *}$ & $-4.069^{* *}$ & $-2.948^{\star *}$ & -0.667 \\
\hline & $(1.084)$ & (1.410) & $(8.047)$ & $(6.650)$ & $(1.734)$ & $(1.400)$ & $(0.772)$ \\
\hline Observations & 2,586 & 2,586 & 2,586 & 2,770 & 2,770 & 2,586 & 2,586 \\
\hline R-squared & 0.720 & 0.713 & 0.890 & 0.893 & 0.887 & & \\
\hline F-statistics & 73.04 & 70.65 & 282.30 & 283.18 & 250.06 & 550.27 & 1053.17 \\
\hline
\end{tabular}

Note: Significant at 1\% $\left(^{* *}\right), 5 \%\left({ }^{* *}\right)$ and $10 \%\left({ }^{*}\right)$. Standard errors robust to arbitrary heteroskedasticity and autocorrelation are in parentheses. Specifications (1) to (3) correspond to the first-stage of the instrumental variable estimates of the main econometric model (specifications (3) and (4) in table 2). Specification (4) is an OLS estimate of the econometric model with operator fixed effects. Specifications (5) and (6) are respectively OLS and IV-GMM estimates of the main econometric model, but with linear specification. Specification (7) replaces the working-age population by the number of subscribers as a proxy for market size. 


\section{A.4 Replication of the findings by Schmutzler (2013)}

Consider a duopoly in which firm $i$ incurs a marginal cost $c_{i}$ that depends on the investment that rises the efficiency by $y_{i}=c_{i}^{0}-c_{i}$. The corresponding cost of investment is $I_{i}=a y_{i}^{2}$. $a$ is a parameter proportional to the cost of investment. $y_{i}^{0}$ is the initial efficiency of firm $i$ when $y_{i}=0$. Firm $i$ chooses investment $y_{i}$ in order to maximize $\pi_{i}\left(y_{i}, y_{j}, \theta\right)$. Maximum profit is written for $j \neq i$ :

$$
\pi_{i}^{*}\left(y_{j}, \theta\right)=\max \left(\pi_{i}\left(y_{i}, y_{j}, \theta\right)-a y_{i}^{2}\right)
$$

Example E5 (Competition à la Hotelling: $\theta=1-t$ )

$$
\pi_{i}=\frac{\left[\left(y_{j}^{0}+y_{j}\right)-\left(y_{i}^{0}+y_{i}\right)-3(1-\theta)\right]^{2}}{18(1-\theta)}
$$

In symmetric duopoly $y_{i}^{*}=y_{j}^{*}=\frac{1}{6 a}$ and $\pi_{i}^{*}\left(y_{i}^{*}, y_{j}^{*}, \theta\right)=\frac{1-\theta}{2}$

Condition of positive profit: $\pi_{i}^{*}\left(y_{i}^{*}, y_{j}^{*}, \theta\right)-a y_{i}^{2}>0$ yields $\theta<1-\frac{1}{18 a}$

The value above which profit is zero is then $\bar{\theta}=1-\frac{1}{18 a}$

$\bar{\theta}$ is increasing in $a$.

This property is checked for all the examples proposed by Schmutzler in symmetric duopoly. $p_{i}$ is the price set by firm $i$ and $q_{i}$ the output of firm $i$.

Example E1: Price competition, demand $p_{i}=1-q_{i}-\theta q_{j}$

Example E2: Quantity competition, demand $p_{i}=1-q_{i}-\theta q_{j}$

Example E3: Price competition, demand $p_{i}=1-\frac{1}{1+\theta} q_{i}-\frac{\theta}{1+\theta} \theta q_{j}$

Example E4: Quantity competition, demand $p_{i}=1-\frac{1}{1+\theta} q_{i}-\frac{\theta}{1+\theta} \theta q_{j}$

Example E5 is simple, the other examples require more tedious calculations: Fig. 3 presents the increasing relationship between $\bar{\theta}$ and $a$ for all the examples. 
Figure 3: The relationship between the cost of investment and positive profit bound of competition

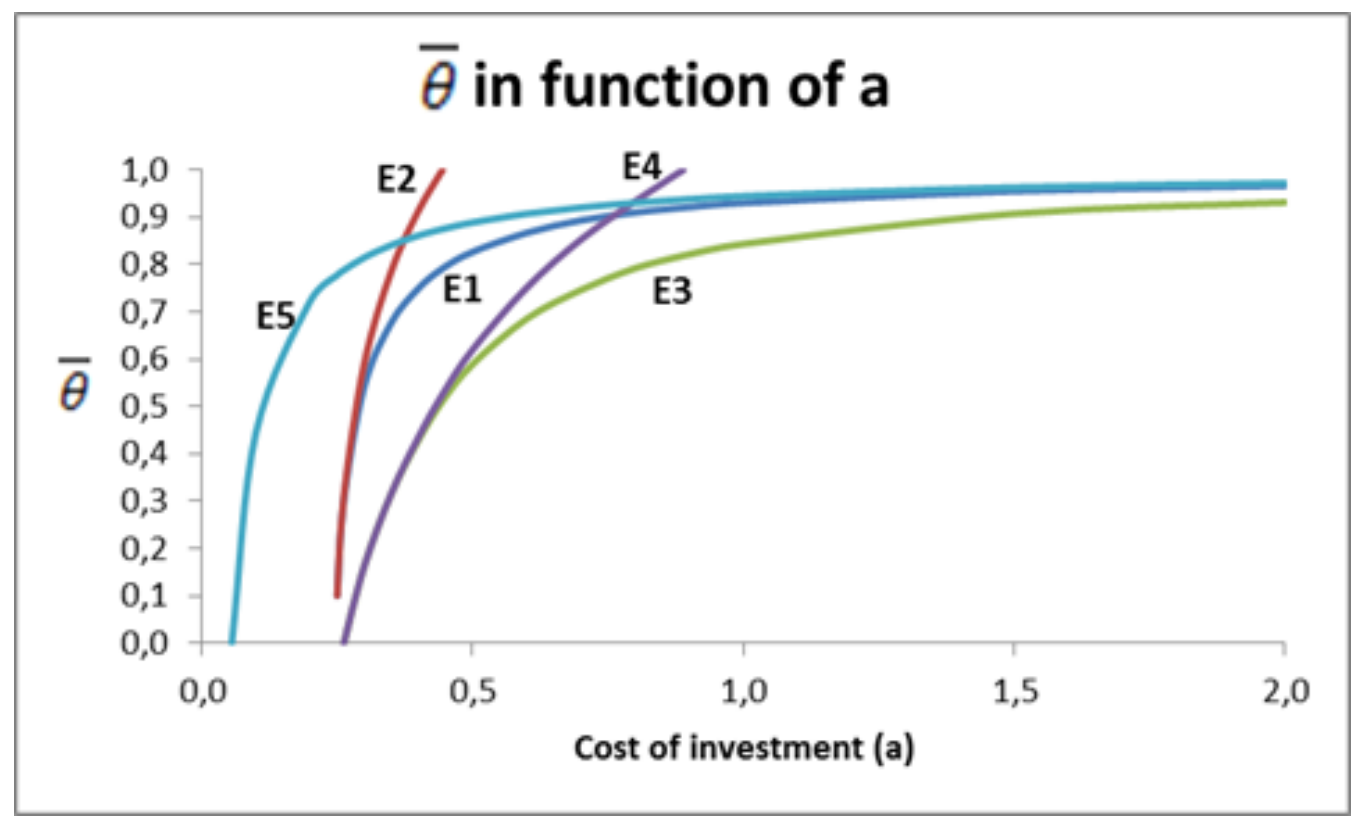

In all cases, $\bar{\theta}$ depends only on $a$. In particular, it does not depend on the initial efficiency $y_{i}^{0}$. For $\theta \leq \bar{\theta}$, firms choose $y_{i}^{*}$, invest $I_{i}^{*}=a y_{i}^{* 2}$ to maximize $\pi_{i}^{*}$. If $\theta>\bar{\theta}$ firms cannot choose $y_{i}^{*}$ because $\pi_{i}^{*}<0$. Therefore, they choose $y_{i}^{* *}<y_{i}^{*}$ such that $\pi_{i}^{* *}\left(y_{i}^{* *}, y_{j}^{* *}, \theta\right)=0$. 